\section{Tin Solders}

A Modern Study of the Properties of Tin Solders and Soldered Joints. By S. J. Nightingale. (Research Monograph No. 1.) Second edition, revised with inclusions of Results of more Recent Research, by Dr. O. F. Hudson. Pp. 118. (London: British Nonferrous Metals Research Association, 1942.) 10s. 6d.

$\mathrm{O}$ $F$ all the common alloys used by the engineer, solder is by far the most expensive. Further, as a result of the temporary loss of the main tin. producing area in the Empire, the utmost economy in the utilization of this metal, an essential ingredient in most solders, is imperative. The present time is, therefore, particularly appropriate for the publication of a second edition of a valuable little compilation which has been out of print for some time.

In its new form, this volume contains considerably more information than did the first edition, particularly in connexion with the metallography and properties of these alloys, and it speaks well for the excellence of the first edition that the part which deals with the more practical considerations and the choice of a suitable solder has required practically no modification.

As one example of the utility of this book, both from the point of view of the information it gives, as well as from that of economy of tin, may be instanced the solder used for production of wiped joints in electric cable sheathing. An earlier specification for such material required about 35 per cent of tin with not more than 0.5 per cent of antimony. It has now been found that an alloy with 30-31 per cent of tin which may contain up to 6 per cent of antimony has superior mechanical properties, gives joints of reduced porosity, and, in the experience of the workers, is easier to manipulate.

Dr. O. F. Hudson, the new editor, and the publishers have done a very useful piece of work.

\section{A Supplement to the Yorkshire Floras}

By the late F. Arnold Lees. Edited by C. A. Cheetham and Dr. W. A. Sledge. Pp. v +134. (London and Hull : A. Brown and Sons, Ltd., n.d.) 6s. net.

7 HE flora of Yorkshire has been described in the volumes on West Yorkshire by F. A. Lees (1888), East Yorkshire by J. F. Robinson (1902) and North Yorkshire by J. G. Baker (1906). Some thirty years ago, Lees collected the additional records and incorporated them in a manuscript entitled the "Vegetation of Yorkshire and Supplement to the Floras of York". This extensive manuscript included, how. ever, so much theoretical discussion relative to the facts embodied that sufficient support could not be found for its publication, though the Yorkshire Naturalists' Union always hoped that the included records might be made available for botanists. This undertaking has now been achieved by Mr. Cheetham and Dr. Sledge and published under the auspices of the Union.

Mr. Cheetham has a very wide knowledge of the flora and has been connected for so long with all aspects of the work of the Union that no one could have been found better able to undertake the work of extracting all reliable data from Lees's manuscript and from the records of the Union. Dr. Sledge has added very many recent records and has revised all the material in the light of the most recent developments in nomenclature and grouping of genera. The volume includes a complete list of the recorded species, including aliens, casuals and escapes which are distinguished typographically from natives, with new recorded localities and points of interest concerning changes in distribution. This cheap and relatively small volume does great credit to the amount of work put into its preparation in order to condense the material to valuable essentials.

\section{The Observer's Book on Astro-Navigation}

By Flight-Lieut. Francis Chichester. Part 4. (Observer's Books, No. 5.) Pp. 152. (London: George Allen and Unwin, Ltd., 1942.) 4s. 6d. net.

TN this, the fourth and concluding portion of Flight1 Lieut. Chichester's book on astro-navigation, a number of important matters are dealt with. These include a description of the flying-boat sextant and the errors that can be introduced into the observations by flight accelerations. The advantage of taking a number of observations at short regular intervals is shown and a brief description is given of the median-marking sextant. The aid to navigation given by running down a position line, when the sun is the only object available for observation, is illus: trated by the record of observations on an actual flight; the method is of special value for flights over the sea, where no landmarks are available for fixing position. The important subject of curved flight corrections is dealt with in some detail. If accurate navigation is required, it is essential to apply corrections for curved flight, due to the rotation of the earth, or to the course steered not being a great circle, or to gyro-wandering. The account of these corrections is somewhat confused, though the method of applying them is clearly explained and illustrated by examples.

The four parts of this book together provide a useful summary of the principles and methods of astro-navigation. Written by a skilled navigator, they contain many practical hints, and any navigator who has mastered their contents cannot fail to benefit from them.

H. S. J.

\section{The Subject Index to Periodicals, 1940}

Pp. xi +230 . (London: The Library Association, 1942.) £3 $17 s$.

$7 \mathrm{HE}$ Subject Index of Periodicals, 1940, issued by the Library Association, publication of which has been considerably delayed by enemy action, covers 534 periodicals, other than those, with some important exceptions, covered by the Agricultural Index, Engineering Abstracts, Engineering Index, Index Medicus, Journal of the Society of Dyers and Colourists, Photographic Abstracts, Bibliography of the Royal Meteorological Society, Science Abstracts, Journal of the Textile Institute, and the Revue des Géologie, Minéralogie et Crystallographie. The number of entries has been diminished owing to the curtailment of the supply of Continental periodicals since 1940, and some of the files of American periodicals are also incomplete. The volume, however, is only about one sixth thinner than the normal volume. The Index is compiled on the plan of the dictionary catalogue, articles being entered under specific headings, in alphabetical order. Explanatory matter is added in square brackets where the titles do not sufficiently indicate the subject of articles. Since September 1940, the editor and his staff have been accommodated in the National Library of Wales, Aberystwyth, although part of the work still has to be done in the British Museum Library. 